\title{
Challenges and directions for the pathogen hypothesis of Alzheimer's disease
}

\author{
Stephen R. Robinson ${ }^{\mathrm{a}, *}$, Curtis Dobson ${ }^{\mathrm{b}}$, Joseph Lyons $^{\mathrm{c}}$ \\ ${ }^{a}$ Department of Psychology, School of Psychology, Psychiatry and Psychological Medicine, Monash University, Clayton, Vic. 3800, Australia \\ ${ }^{\mathrm{b}}$ Molecular Neurobiology Laboratory, Department of Optometry and Neuroscience, UMIST, Manchester, UK \\ ${ }^{\mathrm{c}}$ City of Hope National Medical Center, The Beckman Research Institute, Duarte, CA, USA
}

Received 21 October 2003; received in revised form 21 November 2003; accepted 2 December 2003

\begin{abstract}
This paper critically reviews the possibility that infiltration of the brain by pathogens (e.g. Herpes simplex virus type 1 (HSV1) or Chlamydophila pneumoniae (Cp)) acts as a trigger or co-factor for Alzheimer's disease (AD). The evidence currently available is limited and in some cases inconsistent, but it does justify the need for more vigorous investigation of this hypothesis. An issue of particular concern is the paucity of experimental evidence showing that pathogens can elicit the neuropathological changes and cognitive deficits that characterise AD. Other weaknesses include a failure to obtain independent confirmation of $\mathrm{Cp}$ in $\mathrm{AD}$ brains, and a lack of evidence for HSV1 proteins or intact virions in AD brain tissue. Future avenues of investigation that might prove fruitful include epidemiological investigations of the incidence of AD in individuals who are either immunosuppressed or have received chronic antiviral or antibiotic therapy. There is also a need to consider systemic infections as potential contributors to the pathogenesis of AD.
\end{abstract}

(C) 2004 Elsevier Inc. All rights reserved.

Keywords: Virus; Bacteria; Infection; Amyloid; Plaque; Herpes; Chlamydia

\section{Introduction}

The possibility that infiltration of the brain by pathogens acts as a trigger or co-factor for Alzheimer's disease (AD) has been proposed repeatedly over the past three decades, with Herpes simplex virus type 1 (HSV1) and Chlamydophila pneumoniae $(\mathrm{Cp}$; previously Chlamydia pneumoniae) being most frequently implicated. The initial impetus for this proposal came from the identification of a slow virus-like agent underlying spongiform encephalopathies and the elucidation of the role of the measles and the JC viruses in causing subacute sclerosing panencephalitis and progressive multifocal leukoencephalopathy, respectively $[7,33,40]$. In the mid-1970s several studies compared the levels of HSV1 neutralising antibodies in the serum [29] and cerebrospinal fluid (CSF) [24] of senile patients with various forms of dementia (including $\mathrm{AD}$ ), and in other neurologically impaired and non-neurologically impaired control patients. While these studies found higher antibody levels in patients with $\mathrm{AD}$, later studies failed to confirm such increases [44]. In the 1980s, in situ hybridisation was

\footnotetext{
${ }^{*}$ Corresponding author. Tel.: +61-3-99053903; fax: +61-3-99053948.

E-mail address: stephen.robinson@med.monash.edu.au (S.R. Robinson).
}

used to examine whether HSV1 is present in AD or control brain tissue. Once again, results were inconsistent, with two studies detecting viral nucleic acid in brain $[13,53]$ and another reporting higher levels of HSV1 latency-associated transcripts in AD trigeminal ganglia [9], yet other studies found little or no evidence for the presence of HSV1 nucleic acid [36,42,57]. With the advent of more sensitive techniques (polymerase chain reaction (PCR)), a high proportion of normal elderly and AD brains have been found to contain HSV1 DNA (discussed in [10]). In addition, an association between $\mathrm{Cp}$ and $\mathrm{AD}$ has been demonstrated by the Balin group, initially using PCR but with supporting evidence from other techniques [21].

The preceding observations provide a reason for seriously considering the pathogen hypothesis of $\mathrm{AD}$, particularly since the dominant hypothesis in our field (the amyloid hypothesis) is still open to question (see [47]). Nonetheless, the body of data pertinent to the pathogen hypothesis is small and many key questions remain unanswered. In the interests of accelerating progress in the field, the present paper highlights some of the issues that need to be addressed before this hypothesis can either win widespread acceptance or be rejected for rational scientific reasons. We will begin by examining some of the broad implications of the pathogen hy- 
pothesis and then examine specific data pertaining to HSV1 and $\mathrm{Cp}$ infection of the brain. Throughout this review, we will offer what we consider to be plausible explanations for questions we have raised, in the hope that this will help to guide research into fertile new areas of investigation.

\section{Broad issues}

\subsection{Latency of the pathogen}

Viruses and bacteria infect cells by expressing coat proteins that mimic molecules which are commonly bound and internalised by cells. Each cell type expresses a specific range of receptors, so usually only a subset of cells in an organ is vulnerable to infection by a particular pathogen. Isoform differences in these receptors, which vary according to genotype, further influence susceptibility to infection. PCR studies show that during the first two decades of life a significant proportion (around 20\%) of the human population harbours HSV1 in the trigeminal ganglia [25] from where it can periodically emerge to cause facial blisters in some individuals. This proportion reaches $100 \%$ for individuals aged 50-80 years [25]. Similarly, and based on serological evidence, the majority of people become infected with Cp during the first few decades of life, and are at risk throughout life of becoming re-infected, developing a chronic infection or reactivating a persistent infection [50]. If HSV1 or Cp cause AD, this high rate of infection early in life begs the question: why do the symptoms of $\mathrm{AD}$ not appear until old age? Perhaps such delays result from an age-related decline in the effectiveness of an immune system that becomes increasingly permissive to the migration of pathogens into the brain. This speculation however, has not yet been experimentally tested with respect to HSV1 or Cp.

A second consideration concerning the considerable delay between initial infection and emergence of AD symptoms relates to the complexity of both agents' replicative and developmental cycles during the course of infection. A unique feature of the family of herpesviruses is their ability to infect host cells and then enter a long period of latency during which the viral genome integrates within the host cell's genome and remains inactive [59]. Although mechanistically quite different, $\mathrm{Cp}$ can express a more transient property of incomplete or suspended development and uses an assortment of ways to persist in a hostile environment, including the subversion of host immune responses to infection [49] and avoidance of being killed during what should be adequate antibiotic therapy [31]. These strategies are well documented in vitro and are thought to play a role in chlamydial disease; however, the evidence demonstrating long-term persistence and a role for persistence in disease progression remains circumstantial.

It has been postulated that reactivation of HSV1 and subsequent re-infection of brain tissues occurs irregularly and locally, presumably as a strategy to reduce detection by the immune system [21]. The same would likely hold true for $\mathrm{Cp}$ if it is proven that persistence and resumption of the developmental cycle occur during infection. Through this process, the spread of infection through the nervous system may take many decades. The shingles virus Herpes zoster is an example of a neurotropic virus that displays such a pattern of dormancy followed by occasional reactivation. If the pathogen(s) that causes AD has a long latency it should be present in the brains of a large proportion of cognitively normal individuals, because in these individuals the pathogen would not yet have proliferated to the extent that it would have noticeable effects on cognition. HSV1 has been detected in a large proportion of brains from cognitively normal people [20], but the tight correspondence between Cp in $\mathrm{AD}$ brain and its virtual absence from normal elderly brains [2] does not fit the expected pattern. One of the challenges for proponents of $\mathrm{Cp}$ will be to address this discrepancy.

\subsection{Transmissibility of the pathogen}

In 1977 Gajdusek suggested that AD might be caused by a slow pathogen akin to the agents he had shown to be involved in the transmissible spongiform encephalopathies [15]. This suggestion led to several investigations in which $\mathrm{AD}$ brain homogenates or other tissues were directly injected into primate brains, but none of these experiments were able to demonstrate the transmissibility of AD neuropathology or cognitive impairment [8]. While this lack of evidence for transmissibility presents an obstacle for the pathogen hypothesis, it can be argued that the failure to demonstrate transmission does not disprove the infectious aetiology of a disease, particularly for pathogens with a long latent phase. Latent pathogens (by definition) remain non-transmissible for the majority of their replication cycles. Another reason why transmissibility cannot always be demonstrated in animal models is that pathogens frequently infect cells via receptor isoforms which are species-specific. A well-characterised example is the viral condition of subacute sclerosing panencephalitis, which is transmissible to primates only after careful isolation and passaging of the virus using monkey kidney cell lines [1]. The failure to experimentally infect non-human primates with $\mathrm{AD}$ may therefore reflect a combination of an experimental protocol which did not take into account the properties of latent pathogen infection, and a possible lack of appropriate receptors in these animals.

The lack of evidence for transmissibility does not disprove the pathogen hypothesis of AD. Nonetheless, if the reasons advanced for non-transmissibility can be shown not to apply to HSV1 or $\mathrm{Cp}$, then the likelihood that these particular pathogens cause $\mathrm{AD}$ will be diminished. An informative test would be to directly inoculate the brains of non-human primates with active HSV1 or Cp, and examine the tissue for AD-like changes.

Infection of mouse brain with HSV1 is a common experimental model of Herpes simplex encephalitis (HSE) in hu- 
mans and while it reproduces many of the acute features of the disease, less is known about histopathological changes associated with chronic HSV1 infection in rodent brain [34]. To our knowledge no studies of chronic HSV1 infection of rodent brain have examined tissue for the presence of plaques or tangles, or have investigated whether these animals display learning deficits. Demonstration of such deficits would strengthen the case for a pathogenic cause of AD. Recently Balin's group [27] reported that intranasal inoculation of mice with $\mathrm{Cp}$ isolated from $\mathrm{AD}$ brain tissue results in the deposition of amyloid beta $(A \beta)$ protein in the limbic regions of the mouse brain. These deposits could be immunolabelled by antisera directed against human $A \beta_{1-42}$, they resembled the diffuse plaques seen in elderly human brains and they increased in number, size and density as the infection progressed. While this report demonstrates that pathogens may have the potential to induce one of the neuropathological features of $\mathrm{AD}$, further work is required. In addition to independent replication of this observation, evidence is required to show that $\mathrm{Cp}$ infection can induce neuritic plaques, gliosis, tangles, neuronal degeneration, synaptic loss and progressive cognitive impairment.

\subsection{Involvement of cholinergic pathways}

A characteristic of early-stage AD is a decreased effectiveness of the cholinergic pathways and a reduction in the levels of acetylcholine (ACh) in neurons of the basal forebrain and hippocampus [17]. While the cognitive deficits associated with this decrease can be ameliorated in the early stages of the disease by the administration of acetylcholinesterase inhibitors, progress of the disease is not halted by such therapies [17]. Intensive investigations have failed to provide an adequate explanation for the specific and early involvement of the cholinergic pathways in AD.

It is interesting that the surface glycoprotein D of HSV1 contains an amino acid sequence which closely resembles the $\alpha$-chain of the human ACh receptor (AChR) [11,52]. The homology is so close that vaccination of mice with AChR provides a significant degree of protection against HSV1 infection and reduces fatal encephalitis by $75 \%$, whereas infection by HSV1 elicits autoantibodies that bind to the AChR [16]. The preceding observations do not indicate that AChRs provide a route for HSV1 to infect neurons, but they do suggest that antibodies generated in response to the presence of HSV1 may also bind to AChR at cholinergic synapses thereby interrupting cholinergic neurotransmission. This speculation raises the possibility that the cognitive impairment in the initial stages of AD, which appears to be due to a decreased effectiveness of cholinergic neurotransmission, may correspond to a period of reactivation of HSV1 and an associated increase in the expression of antibodies that recognise AChRs. This possibility might be investigated by obtaining longitudinal data concerning the status of HSV1 infection in elderly individuals who suffer from mild cognitive impairment and may be in the preclinical stages of AD.
Cp infection may also be linked to the cholinergic pathways. It is noteworthy that the activation of nicotinic AChR by $\mathrm{ACh}$ or nicotine facilitates the growth of $\mathrm{Cp}$ in cultured epithelial cells that have been infected with the bacteria. The growth-promoting effects can be completely blocked by non-selective nicotinic AChR agonists [62]. This result raises the interesting speculation that if antibodies are generated to glycoprotein D of HSV1 in AD, their capacity to cross react with AChR might simultaneously slow the proliferation of $\mathrm{Cp}$.

\subsection{Inherited forms of $A D$}

Genetic studies of autosomal familial AD have established that mutations in the amyloid precursor protein (APP) gene and related presenilin (PS) genes can cause early onset AD. Individuals with trisomy 21 are also predisposed to the development of neurodegenerative and cognitive changes that closely resemble AD. The involvement of several genes that each cause early onset $\mathrm{AD}$ is sometimes interpreted to indicate that $\mathrm{AD}$ is a multifactorial disease without a single cause. This interpretation is favoured by adherents of the pathogen hypothesis, who have focussed on sporadic forms of AD. However, one of us has noted elsewhere [47] that the genes which give rise to autosomal familial AD may not necessarily cause AD. Instead they may be risk factors that greatly enhance the susceptibility of an individual to an ubiquitous extrinsic agent. For example, if sporadic $\mathrm{AD}$ is caused by a pathogen that is present in the brains of most (or all) adults, it is possible that some genetic mutations may potentiate the neuronal injury caused by this pathogen. Thus, the mutations that are currently thought to directly cause the disease may actually be cofactors which accelerate the neurodegenerative process caused by a pathogen. This idea may explain why carriers of genes for autosomal familial AD only develop the disease after expressing the genes for half a century or more, instead of developing AD during their childhood, but still much sooner and more predictably than non-familial sporadic AD.

At present there is no evidence that carriers of APP and PS mutations or trisomy 21 are predisposed to a negative response to neural infection, but it may be pertinent that in Down syndrome the activity of myeloperoxidase in polymorphonuclear leukocytes is reduced to only $59 \%$ of the level seen in unaffected individuals $[4,14]$. This enzyme represents one of the principal defences of neutrophils and macrophages against bacterial and viral infection. The reduction in myeloperoxidase activity in Down syndrome is likely to contribute to the increased susceptibility to infections of the respiratory tract, such as pneumonia [4,37]. It remains to be established however, whether susceptibility to and/or severity of infection with Cp and HSV1 is greater in Down syndrome or carriers of autosomal familial AD, and if Cp or HSV1 levels are prematurely elevated in brain tissue affected by either of these conditions. 


\subsection{Immunosuppression challenges the pathogen hypothesis}

Individuals who receive immunosuppressive drugs to prevent the rejection of transplanted tissues by the host immune system frequently display secondary complications associated with the reactivation of endogenous pathogens. These pathogens often belong to the herpesvirus family. An example is cytomegalovirus (CMV) infection which has been reported in 54\% of kidney transplant patients [56], and CMV DNA amplification has been reported in the brains of $51 \%$ of liver transplant patients compared with only $14 \%$ of controls [45]. Similarly, a substantial body of evidence indicates that reactivation of human herpes virus- 6 is a significant cause of post-transplantation encephalitis in bone marrow transplant recipients $[28,54]$. If a common endogenous pathogen causes $\mathrm{AD}$, individuals with suppressed immune systems might be expected to display progressive cognitive decline and AD-like neuropathology as a result of their treatment. The fact that this does not occur presents a significant challenge for proponents of the pathogen hypothesis of AD.

\subsection{Proof of concept and animal models}

Any hypothesis that attempts to explain how an agent causes AD must be able to account for the spatiotemporal spread of neuritic plaques in the brain, which after all, are the defining pathological hallmarks of the disease. The hypothesis should be able to adequately explain why plaques form initially in the inferior regions of cerebral cortex and then spread to other cortical regions, leaving the occipital cortex, cerebellum and brainstem relatively unaffected; and it should explain why plaques do not form throughout life. An appealing feature of the pathogen hypothesis is that it can potentially account for these spatiotemporal features of plaque formation. One of us has proposed that soluble $A \beta$ may bind pathogens, proteins and toxic metal ions, and then precipitate to stimulate a phagocytic response from macrophages and glial cells $[3,47]$. This 'bioflocculant hypothesis' provides a link between pathogen infection of the brain and the occurrence of $\mathrm{A} \beta$ deposits. Thus, the presence of newly formed plaques might be indicative of a local phase of reactivation, whereas old plaques might indicate the location of an earlier reactivation. The bioflocculant hypothesis predicts that some, but not all $\mathrm{A} \beta$ plaques, are likely to contain viral or bacterial particles, or their coat proteins. As yet, this possibility has not been investigated with respect to HSV1, but Balin et al. [2] have reported that a proportion of $A \beta$ plaques in $\mathrm{AD}$ brains do contain antigens which are recognised by antisera that are specific for $\mathrm{Cp}$. This finding has not been independently confirmed, so a more detailed investigation of the colocalisation of $A \beta$ and pathogen markers would help to strengthen both hypotheses.

Some transgenic mouse lines that overexpress mutated human APP genes acquire high burdens of $A \beta$ plaques in their cerebral cortices. These deposits are associated with gliosis and are accompanied by impaired performance on certain maze tasks (for review see [47]). Such mouse models have done much to support the claim that $A \beta$ deposition contributes to some of the neuropathological and behavioural features of AD. Until recently the greatest weakness of the pathogen hypothesis has been a failure to demonstrate a similar causal relationship between pathogen infection of the brain and the development of cognitive decline and neurodegenerative changes that are typical of AD. However, Little et al. [27] have reported that intranasal infection of mice with $\mathrm{Cp}$ triggers a time-dependent increase in $\mathrm{A} \beta$-immunoreactive deposits in the brain tissue. Most of these deposits resemble diffuse plaques and have no associated gliosis but a small proportion contain fibrillar $\mathrm{A} \beta$, as evidenced by thioflavin- $S$ staining. No neuritic changes or neurofibrillary tangles were reported and it is not known whether these animals have cognitive impairments. While these observations provide a first step towards proof-of-concept, the fact that APP transgenic mice are specific pathogen free (SPF) yet can develop $A \beta_{1-42}$ deposits appears to indicate that infectious agents are not a prerequisite for the development of plaques in animal models of $\mathrm{A} \beta$ deposition. It would be interesting to determine whether infection of such mice with HSV1 or Cp enhances the development of AD-like neuropathology in these animals.

\section{HSV1 infection of brain}

\subsection{Herpes simplex encephalitis}

In rare instances, HSV1 causes HSE in immunocompetent individuals. Around 2-4 HSE cases occur per million individuals per annum; if untreated, the disease is fatal in over $70 \%$ of cases [60], with death occurring within a few days of manifestation of symptoms. Since HSV1 infection of brain is also postulated to cause $\mathrm{AD}$, it is instructive to compare the clinical and neuropathological symptoms of HSE with those of AD.

Table 1 shows that there are some clinicopathological similarities between HSE and AD, yet there are some notable differences, such as the lack of haemorrhagic lesions in AD. It should be noted that HSE involves an acute infection of the brain whereas $\mathrm{AD}$ may reflect the consequences of chronic infection, and so the route of infection and the factors influencing its spread may be different. The existence of such differences is emphasised by the fact that the incidence of HSE is significantly higher for carriers of APOE- 2 [26], whereas in AD HSV1 is more frequently detected in the brains of APOE- $\varepsilon 4$ carriers than in APOE- $\varepsilon 3$ carriers; and is more likely on reactivation to cause herpes labialis in APOE- $\varepsilon 4$ carriers [20]. It is common for acute and chronic variants of infectious diseases to have different symptoms. For example, the features of acute Herpes zoster infection (chickenpox) differ substantially from chronic Herpes zoster infection (shingles). Notwithstanding this point, there are some 
Table 1

Comparison of the clinical and neuropathological features of HSE with those of AD

\begin{tabular}{|c|c|}
\hline HSE & $\mathrm{AD}$ \\
\hline $\begin{array}{l}\text { Increased CSF pressure and pleocytosis (10-500 lymphocytes per } \\
\text { millilitre of CSF). }\end{array}$ & $\begin{array}{l}\text { CSF pressure is normal but there is mild pleocytosis }(10-200 \\
\text { lymphocytes per millilitre of CSF). }\end{array}$ \\
\hline Increased CSF protein content. & $\begin{array}{l}\text { Increased CSF content of certain proteins (e.g. glutamine synthetase, } \\
\text { Tau, GFAP, neuropil thread protein, } S 100 \beta \text { ) }\end{array}$ \\
\hline Intense haemorrhagic necrotic lesions. & Not present. \\
\hline Cerebral amyloid angiopathy has not been reported. & Cerebral amyloid angiopathy is common in the majority of cases. \\
\hline Asymmetric/unilateral involvement of the hemispheres. & Spread of neuropathology is generally (but not always) symmetrical. \\
\hline Tangles were reported in an early study [22]; no reports of plaques. & Plaques and tangles are a definitive feature of the disease. \\
\hline Motor impairments and convulsions are common. & $\begin{array}{l}\text { Motor impairments and convulsions are uncommon except at endstages } \\
\text { of advanced AD. }\end{array}$ \\
\hline $\begin{array}{l}\text { Personality change, alteration of consciousness, headache, fever, } \\
\text { dysphasia during acute phase. Persistent memory impairment and } \\
\text { impairment of other cognitive functions at subsequent stages. }\end{array}$ & $\begin{array}{l}\text { Progressive memory impairment, erosion of other cognitive functions, } \\
\text { personality changes. }\end{array}$ \\
\hline Swelling and herniation of the temporal lobes through the tentorium. & Oedema not reported. \\
\hline Degeneration and shrinkage of temporal lobes after recovery. & Atrophy of neuropil and corresponding ventricular enlargement. \\
\hline $\begin{array}{l}\text { Hypermetabolism of glucose during acute phase; post-infection } \\
\text { hypometabolism reported in one patient [35]. }\end{array}$ & Hypometabolism of glucose by cerebral cortex. \\
\hline $\begin{array}{l}\text { Animal studies suggest that cholinergic and other neurotransmitter } \\
\text { systems are unaffected. }\end{array}$ & Loss of cholinergic innervation to cerebral cortex. \\
\hline $\begin{array}{l}\text { Initial focus of infection is in inferior temporal and inferior frontal } \\
\text { cortices and hippocampal formation. }\end{array}$ & $\begin{array}{l}\text { Initial focus of infection is in inferior temporal and inferior frontal } \\
\text { cortices and hippocampal formation. }\end{array}$ \\
\hline
\end{tabular}

features of AD that should be expected if HSV1 does cause $\mathrm{AD}$. In particular, one might expect to find $\mathrm{A} \beta$ plaques and tau + tangles in affected regions of the HSE affected brain, at least during the recovery phase. Post-mortem brain tissue from this stage of the disease is rare, but examination of even a small number of cases might provide insights into the link between HSV1 and AD.

\subsection{Absence of HSV1 particles and viral antigen in $A D$}

Although HSV1 DNA appears to be prevalent in human brain, neither HSV1 proteins nor intact virions have been detected in $\mathrm{AD}$ brain tissue, except in an early study which reported HSV1 proteins in 2/40 brains (one from an AD patient, the other a control) [32]. On the face of it, these results indicate that HSV1 infection of brain is non-productive and therefore irrelevant to AD. However, HSV1 proteins are not even detectable in the brains of HSE patients once the acute phase of infection is over, despite the high levels which would have been present during the acute phase, and despite the presence of detectable viral DNA many years later [23]. Thus, it appears that HSV1 proteins produced during an acute infection are rapidly cleared, and are not detectable during latency (i.e. most of the time). This limitation poses difficulties for proponents and opponents of the pathogen hypothesis. However, the pathogen cannot always be latent, as it must reactivate sporadically for $\mathrm{AD}$ to progress, so a proportion of $\mathrm{AD}$ patients should have active pathogen in some parts of their brain. It is possible that Mann and colleagues [32] detected this transient expression in two of the brains they examined. One of the challenges faced by proponents of HSV1, will be to prove this to be the case in a larger sample of brains.

\subsection{Causality and therapeutic drugs}

Even if the presence of a pathogen in post-mortem tissue was found to be unambiguously correlated with $\mathrm{AD}$, this association alone would not prove that the former caused the latter. AD patients are often very ill and malnourished prior to death. This poor health may favour pathogen proliferation within the brain antemortem (increasing the likelihood of detectable levels of pathogen), and may increase the risk of primary infection. Additional evidence is needed to show causality. A causal relationship can be established if removal of the agent from the human brain halts, reverses or prevents the disease. Here at least, proponents of the pathogen hypothesis are at an advantage, in that effective pharmaceuticals for treating brain infection are readily available. Thus, a causal role for pathogens in $\mathrm{AD}$ is readily testable, should sufficient evidence be gathered to justify clinical trials of these drugs.

Although of low incidence, most acute infections of the brain are effectively treated with broad spectrum antiviral and/or antibacterial regimes. HSE for example, can be treated with Acyclovir (10-15 mg/kg bodyweight every 6-8 h) for at least 10-14 days [51]. It should be noted that Acyclovir cannot eliminate pathogens from the brain: it can only stop them from replicating during therapy. The virus will remain latent (i.e. no virus particles, only DNA) and it may eventually reactivate. Some persistent conditions (e.g. recurrent Herpes labialis), must be treated with oral administration of Acyclovir for many years [61]. Should $\mathrm{AD}$ be triggered by periodic reactivation of virus within the CNS, one might expect reactivation to be less frequent in individuals who receive chronic treatment with Acyclovir, and therefore the incidence of $\mathrm{AD}$ should be lower in 
these individuals. An epidemiological investigation of this possibility might provide a fruitful line of inquiry.

The antibiotic clioquinol is currently in clinical trials as a potential treatment for $\mathrm{AD}$ [12]. This drug readily crosses the blood-brain barrier and is being used because it has powerful metal chelating properties. Ironically, if this drug is successful at slowing the course of $\mathrm{AD}$ we will not know whether it is due to the removal of metal ions or the elimination of bacterial infection from the brain. On the other hand, given its intracellular location, $\mathrm{Cp}$ might be able to survive on host cell stores which could not be depleted to levels incompatible with their survival.

We are unaware of any clinical trials that have specifically used antiviral agents as a treatment for AD. However, several such drugs are already approved for use in the elderly, and since they have relatively few contraindications, the most direct way to test the involvement of HSV1 would be to administer antiviral agents to patients with mild AD or mild cognitive impairment. This might prove to be a cheaper, quicker and safer intervention than the more controversial approaches that are currently being trialed on the basis of the amyloid hypothesis [48]. Optimism for this approach must be tempered by the consideration that life-long administration might be required to prevent recurrent infection resulting from reactivation of latent pathogens. In the case of ubiquitous pathogens like HSV1 and Cp, the final proof of their participation may not come until effective vaccines are developed.

\section{Chlamydophila pneumoniae infection of brain}

Unlike HSV1, the challenge to human health posed by the obligate intracellular bacteria $C$. pneumoniae has become apparent only during the last 20 years, with its possible role in non-respiratory diseases being the object of serious investigation for less than a decade. Cp belongs to the family of bacteria, Chlamydiaceae, that contains members which cause diseases of varied severity and variable pathologic outcome both at the site of initial infection and systemically. Coincidental with its identification as a primary aetiologic agent of community acquired pneumonia, growing understanding of the complexity of the mechanisms involved in chlamydia-associated pathologic processes make pathogens belonging to this family ideal candidates for participation in chronic and unpredictable pathologies like AD. An appreciation of this potential is reflected by its inclusion in a panel of conventional infectious agents that were investigated in an early sero-epidemiologic study [44] to consider if an association between infection and AD could be established. However, no significant differences were found between AD patients and controls for any of the agents tested, which in addition to $\mathrm{Cp}$, included HSV1. The authors concluded that these agents play no role in the aetiology of AD. That study and its conclusion served as the only reference addressing the question of chlamydial involvement in AD until the study of Balin et al. [2] in which an almost pathognomonic association between $\mathrm{Cp}$ and $\mathrm{AD}$ was compellingly demonstrated.

\subsection{Evidence for $C p$ in $A D$}

Balin et al. [2] reported that $\mathrm{Cp}$ was definitively present in brain samples from 17 of 19 post-mortem confirmed cases of late-onset $\mathrm{AD}$, while being detected in only 1 of 18 non-AD, age matched controls. This elegant study employed a number of methodologies (PCR, immunohistochemistry and culture) not only to detect $\mathrm{Cp}$ and visualise it within cells of the CNS that were associated with plaques and tangles, but most definitively, to culture $\mathrm{Cp}$ from tissue homogenates of the two specimens that afforded enough tissue on which to make the attempt. Needless to say, this report received a great deal of public and scientific attention and attempts to replicate the finding were conducted in other reputable laboratories throughout the world. Two abstracts are often cited as confirmation of the initial findings $[30,39]$ but neither has been published in a peer-reviewed format. By contrast, four independent papers $[18,38,46,58]$ have reported an inability to detect $\mathrm{Cp}$ in brain samples from either $\mathrm{AD}$ or non-AD sources. Worthy of note is the most recent of these studies [58] which included 19 samples from 10 of the brain specimens included in the original Balin study; none were found to contain detectable $\mathrm{Cp}$ antigen or PCR products despite the use of primers against the same genes probed in the original study. Since PCR is a capricious technique, it might be argued that these results are 'false negatives' and that a positive result carries more weight than a negative one. This argument cannot be entirely dismissed, but it does overlook the fact that $\mathrm{Cp}$ has been independently reported to be associated with multiple sclerosis and atherosclerosis despite similar methodological discrepancies and conflicting results between research groups. In both cases, the number of published studies confirming an association are far fewer than those in which no association was observed, leading most chlamydiologists to hold a guarded opinion as to whether this association is causal, contributory, or merely coincidental.

One of us was involved in a study [46] that did not confirm the presence of Cp by PCR or culture in samples from numerous sites within the brains of 15 cases of pathologically confirmed AD. Every effort was made to faithfully reproduce the methods used in the original study and to provide a reasonable explanation for the completely opposing results. It was suggested that demographic differences between the patient groups, such as geographic location, season of death and institutional history might provide an explanation for the observed differences. The speculation being that the $\mathrm{AD}$ patients in the Balin study might have been recently exposed to $\mathrm{Cp}$, perhaps in an institutional setting, and therefore would have been at high risk of systemic spread from the respiratory tract to sites within the CNS where advanced AD pathology already existed. In fact, the histological description, the ease of detecting intact inclusions and $\mathrm{Cp}$ antigens, and particu- 
larly the isolation of viable bacteria are all features consistent with an acute and active infection rather than a chronic one. By contrast, a chronic infection, as is thought to occur in the association of $\mathrm{Cp}$ with atherosclerosis, would be expected to frequently present with false negative or difficult to obtain positive results and culture negativity, given the low numbers of predominantly non-infectious $\mathrm{Cp}$ particles characteristic of chronic infection. Although the activation of a chronic infection cannot be ruled out, the simultaneous occurrence of such an event exclusively within the entire $\mathrm{AD}$ cohort would call for an explanation, perhaps requiring it to be listed as a possible cause of death.

\subsection{Potential for involvement of $C p$ in $A D$}

On balance, the data presently available do not support the hypothesis that $\mathrm{AD}$ is caused by chronic infiltration of the brain by $\mathrm{Cp}$. It remains possible however, that acute or chronic $\mathrm{Cp}$ infections do contribute to the pathogenesis of $\mathrm{AD}$ in a proportion of cases. $\mathrm{Cp}$ has many attributes that make it a potential contributor to the progressive neurodegeneration seen in AD. Multiple respiratory infections with chronic sequelae are very common, with seroprevalence increasing throughout life and reaching a prevalence in excess of $75 \%$ among the elderly [5]. Cp is an obligate intracellular bacterium that has been shown in vitro to productively infect a wide range of cell types including epithelial, vascular endothelial and macrophage-derived cell lines; and it has been detected in various stages of development, from productive to persistent, in similar cell types throughout the human body. Like most intracellular pathogens, it interferes with the normal apoptotic signalling pathways of these cells, perhaps contributing to long-term persistence. Cp can trigger the differentiation of monocytes into macrophages, and can persist in, and activate macrophages, which at least in vitro, can traffic across the vascular endothelium. It is a gram-negative bacterium and thus produces endotoxin and, like all bacteria, has CpG motifs in its DNA, both of which are specific ligands for Toll-like receptors, the recently identified signalling molecules of the innate immune system [43]. In short, it is the type of organism that could contribute both directly and indirectly to the kind of inflammatory degeneration seen in association with $\mathrm{AD}$ lesions.

The current state of controversy in this area resembles the uncertainty that followed the first conflicting publications addressing the association of $\mathrm{Cp}$ and atherosclerosis. Since then numerous studies have conclusively demonstrated its presence within atherosclerotic plaques, with serious consideration being given to a speculation that it might be present in all atheromatous lesions [6]. Others have convincingly detected $\mathrm{Cp}$ in the synovial tissue of some patients with reactive arthritis. $\mathrm{Cp}$ has been detected by PCR in the cerebrospinal fluid of $96 \%$ of multiple sclerosis patients and in only $18 \%$ of controls [55], a finding that has been confirmed by some but not all studies. What is common to all these diseases, including AD, is a chronic degenerative process in which activated macrophages or macrophage-like cells participate. What is being proposed by proponents of pathogen hypotheses in each of these diseases is that the activated state of these cells, and therefore the inflammatory degenerative processes in which they participate, is due to an association with $\mathrm{Cp}$ either as a result of attraction to a site of active infection or, subsequent to such an encounter, the systemic transport of the agent to another site where the signature pathology develops. If $\mathrm{Cp}$ is involved in sporadic $\mathrm{AD}$, it seems likely that $\mathrm{Cp}$ would be delivered to the CNS where it would contribute to the development of plaques, tangles and neurodegeneration. However, to date the only study linking $\mathrm{Cp}$ with $\mathrm{AD}$ has yet to be independently confirmed, and the animal model developed by the same group and described at a number of scientific meetings has yet to be replicated by others. Both of these things must occur if the pathogen hypothesis, as it relates to $\mathrm{Cp}$, is to be advanced.

\section{Summary and conclusions}

The pathogen hypothesis of $\mathrm{AD}$ was postulated several decades ago but has not yet been subjected to a rigorous attempt at falsification. The fragmentary evidence currently available either provide qualified support for the hypothesis, or at least do not conclusively disprove it. In the spirit of constructive criticism we have highlighted aspects of the hypothesis that require investigation or are represented by contradictory data. Issues of particular concern include:

(1) paucity of evidence from an animal model that an experimentally introduced pathogen can elicit the neuropathological changes and cognitive deficits that characterise AD;

(2) lack of evidence for HSV1 proteins or intact virions in AD brain tissue;

(3) failure to obtain independent confirmation of $\mathrm{Cp}$ infection of brain in AD.

Future avenues of investigation that might prove fruitful include epidemiological investigations of the incidence of $\mathrm{AD}$ in individuals who are either immunosuppressed patients or have received chronic antiviral or antibiotic therapy.

We will conclude by suggesting that numerous infectious agents, now studied in isolation or not at all, may together contribute to an ongoing and life-long interaction between the brain and body. A recent review noted that during systemic infections, cytokines and molecules associated with the infectious agent are released into the circulation and cross the blood-brain barrier where they can activate microglial cells [41]. Furthermore, a prospective study which charted the course of systemic infections and cognitive decline in AD patients noted that periods of decline were preceded by infection-induced increases in interleukin $1 \beta$, a cytokine considered to play a significant role in neurodegenerative processes, and which can cross the blood-brain barrier and further activate reactive microglia [19]. Both of 
these studies draw attention to the need to consider systemic infections as a class of aetiologic agent, which when viewed in the collective may add to the credibility of the pathogen hypothesis of $\mathrm{AD}$ in a way that the study of single agents may never allow.

\section{Acknowledgments}

We thank Drs. Keith Crutcher and Glenda Bishop for providing constructive suggestions on the manuscript.

\section{References}

[1] Albrecht P, Burnstein T, Klutch MJ, Hicks HT, Ennis FA. Subacute sclerosing panencephalitis: experimental infection in primates. Science 1977;195(4273):64-6.

[2] Balin BJ, Gerard HC, Arking EJ, Appelt DM, Branigan PJ, Abrams JT, et al. Identification and localization of Chlamydia pneumoniae in the Alzheimer's brain. Med Microbiol Immunol (Berl) 1998;187(1):23-42.

[3] Bishop GM, Robinson SR. The amyloid hypothesis: let sleeping dogmas lie. Neurobiol Aging 2002;23(6):1101-5.

[4] Bjorksten B, Marklund S, Hagglof B. Enzymes of leukocyte oxidative metabolism in Down's syndrome. Acta Paediatr Scand 1984;73(1):97-101.

[5] Campbell LA, Kuo CC, Grayston JT. Chlamydia pneumoniae and cardiovascular disease. Emerg Infect Dis 1998;4(4):571-9.

[6] Cochrane M, Pospischil A, Walker P. The location and number of sections required to increase the chance of detecting Chlamydia pneumoniae in atherosclerotic carotid arteries. In: Schachter J, Christiansen G, Clarke IN, editors. Chlamydia infections. Proceedings of 10th International Symposium on Human Chlamydial Infections. Antalya, Turkey; 2002. p. 301-4.

[7] Connolly JH, Allen IV, Hurwitz LJ, Millar JHD. Measles-virus antibody and antigen in subacute sclerosing panencephalitis. Lancet 1967;289:524-44.

[8] Corsellis JA. The transmissibility of dementia. $\mathrm{Br}$ Med Bull 1986;42(1):111-4

[9] Deatly AM, Haase AT, Fewster PH, Lewis E, Ball MJ. Human herpes virus infections and Alzheimer's disease. Neuropathol Appl Neurobiol 1990;16(3):213-23.

[10] Dobson CB, Itzhaki RF. Herpes simplex virus type 1 and Alzheimer's disease. Neurobiol Aging 1999;20(4):457-65.

[11] Dyrberg T, Petersen JS, Oldstone MB. Immunological cross-reactivity between mimicking epitopes on a virus protein and a human autoantigen depends on a single amino acid residue. Clin Immunol Immunopathol 1990;54(2):290-7.

[12] Finefrock AE, Bush AI, Doraiswamy PM. Current status of metals as therapeutic targets in Alzheimer's disease. J Am Geriatr Soc 2003;51(8):1143-8.

[13] Fraser NW, Lawrence WC, Wroblewska Z, Gilden DH, Koprowski H. Herpes simplex type 1 DNA in human brain tissue. Proc Natl Acad Sci USA 1981;78(10):6461-5.

[14] Gabbianelli R, Kantar A, Oggiano N, Fiorini R, Falcioni G, Giorgi PL. Oxidative metabolism in polymorphonuclear granulocytes of children with trisomy 21. Minerva Pediatr 1993;45(12):493-7.

[15] Gajdusek DC. Unconventional viruses and the origin and disappearance of kuru. Science 1977;197:943-60.

[16] Gebhardt BM. Evidence for antigenic cross-reactivity between herpesvirus and the acetylcholine receptor. J Neuroimmunol 2000;105(2):145-53.

[17] Giacobini E. Cholinergic function and Alzheimer's disease. Int J Geriatr Psychiatry 2003;18(Suppl 1):S1-5.
[18] Gieffers J, Reusche E, Solbach W, Maass M. Failure to detect Chlamydia pneumoniae in brain sections of Alzheimer's disease patients. J Clin Microbiol 2000;38(2):881-2.

[19] Holmes C, El-Okl M, Williams AL, Cunningham C, Wilcockson D, Perry VH. Systemic infection, interleukin 1beta, and cognitive decline in Alzheimer's disease. J Neurol Neurosurg Psychiatry 2003;74(6):788-9.

[20] Itzhaki RF, Lin WR, Shang D, Wilcock GK, Faragher B, Jamieson GA. Herpes simplex virus type 1 in brain and risk of Alzheimer's disease. Lancet 1997;349(9047):241-4.

[21] Itzhaki RF, Wozniak MA, Appelt DM, Balin BJ. Infiltration of the brain by pathogens causes Alzheimer's disease. Neurobiol Aging, this issue.

[22] Krucke W. Herpes simplex virus und Nervensystem. Jarbuch der Max Planck Gesellschaft zur Forderung der Wissenschaften 1960;70-84.

[23] Lellouch-Tubiana A, Fohlen M, Robain O, Rozenberg F. Immunocytochemical characterization of long-term persistent immune activation in human brain after Herpes simplex encephalitis. Neuropathol Appl Neurobiol 2000;26(3):285-94.

[24] Libikova H, Pogady J, Wiedermann V, Breier S. Search for herpetic antibodies in the cerebrospinal fluid in senile dementia and mental retardation. Acta Virol 1975;19(6):493-5.

[25] Liedtke W, Opalka B, Zimmermann CW, Lignitz E. Age distribution of latent Herpes simplex virus 1 and varicella-zoster virus genome in human nervous tissue. J Neurol Sci 1993;116(1):6-11.

[26] Lin WR, Wozniak MA, Esiri MM, Klenerman P, Itzhaki RF. Herpes simplex encephalitis: involvement of apolipoprotein E genotype. J Neurol Neurosurg Psychiatry 2001;70(1):117-9.

[27] Little CS, Hammond CJ, MacIntyre A, Balin BJ, Appelt DM Chlamydia pneumoniae induces Alzheimer-like amyloid plaques in brains of BALB/c mice. Neurobiol Aging 2004;25(4):419-29.

[28] Ljungman P. Beta-herpesvirus challenges in the transplant recipient. J Infect Dis 2002;186(Suppl 1):S99-S109.

[29] Lycke E, Norrby R, Roos BE. A serological study on mentally ill patients with particular reference to the prevalence of herpes virus infections. Br J Psychiatry 1974;124(0):273-9.

[30] Mahony J, Woulfel J, Munoz D, Chong S, Smieja M. Chlamydia pneumoniae in the Alzheimer's brain-is detection hampered by low copy number? In: Proceedings of 4th Meeting of the European Society for Chlamydia Research, Helsinki, Finland; 2000. p. $299-300$

[31] Malinverni R, Kuo CC, Campbell LA, Lee A, Grayston JT. Effects of two antibiotic regimens on course and persistence of experimental Chlamydia pneumoniae TWAR pneumonitis. Antimicrob Agents Chemother 1995;39(1):45-9.

[32] Mann DM, Tinkler AM, Yates PO. Neurological disease and Herpes simplex virus. An immunohistochemical study. Acta Neuropathol (Berl) 1983;60(1/2):24-8.

[33] Marx JL. Slow viruses II: the unconventional agents. Science 1973;181:44-5.

[34] Meyding-Lamade U, Lamade W, Kehm R, Knopf KW, Hess T, Gosztonyi G, et al. Herpes simplex virus encephalitis: cranial magnetic resonance imaging and neuropathology in a mouse model. Neurosci Lett 1998;248(1):13-6.

[35] Meyer MA, Hubner KF, Raja S, Hunter K, Paulsen WA. Sequential positron emission tomographic evaluations of brain metabolism in acute herpes encephalitis. J Neuroimaging 1994;4:104-5.

[36] Middleton PJ, Petric M, Kozak M, Rewcastle NB, McLachlan DR. Herpes-simplex viral genome and senile and presenile dementias of Alzheimer and Pick. Lancet 1980;1(8176):1038.

[37] Mills EL, Quie PG. Congenital disorders of the function of polymorphonuclear neutrophils. Rev Infect Dis 1980;2(3):505-17.

[38] Nochlin D, Shaw CM, Campbell LA, Kuo CC. Failure to detect Chlamydia pneumoniae in brain tissues of Alzheimer's disease. Neurology 1999;53(8):1888

[39] Ossewaarde JM, Gielis-Proper SK, Meijer A, Roholl PJM. Chlamydia pneumoniae antigens are present in the brains of Alzheimer patients, 
but not in the brains of patients with other dementias. In: Proceedings of 4th Meeting of the European Society for Chlamydia Research, Helsinki, Finland; 2000. p. 301-2.

[40] Penney Jr JB, Weiner LP, Herndon RM, Narayan O, Johnson RT. Virions from progressive multifocal leukoencephalopathy: rapid serological identification by electron microscopy. Science 1972;178(56):60-2.

[41] Perry VH, Newman TA, Cunningham C. The impact of systemic infection on the progression of neurodegenerative disease. Nat Rev Neurosci 2003;4(2):103-12.

[42] Pogo BG, Casals J, Elizan TS. A study of viral genomes and antigens in brains of patients with Alzheimer's disease. Brain 1987;110:90715.

[43] Prebeck S, Kirschning C, Durr S, da Costa C, Donath B, Brand $\mathrm{K}$, et al. Predominant role of toll-like receptor 2 versus 4 in Chlamydia pneumoniae-induced activation of dendritic cells. J Immunol 2001;167(6):3316-23.

[44] Renvoize EB, Awad IO, Hambling MH. A sero-epidemiological study of conventional infectious agents in Alzheimer's disease. Age Ageing 1987;16(5):311-4.

[45] Ribalta T, Martinez AJ, Jares P, Muntane J, Miquel R, Claramonte $\mathrm{X}$, et al. Presence of occult cytomegalovirus infection in the brain after orthotopic liver transplantation. An autopsy study of 83 cases. Virchows Arch 2002;440(2):166-71.

[46] Ring RH, Lyons JM. Failure to detect Chlamydia pneumoniae in the late-onset Alzheimer's brain. J Clin Microbiol 2000;38(7):2591-4.

[47] Robinson SR, Bishop GM. Abeta as a bioflocculant: implications for the amyloid hypothesis of Alzheimer's disease. Neurobiol Aging 2002;23(6):1051-72.

[48] Robinson SR, Bishop GM, Munch G. Alzheimer vaccine: amyloidbeta on trial. Bioessays 2003;25(3):283-8.

[49] Rottenberg ME, Gigliotti-Rothfuchs A, Wigzell H. The role of IFNgamma in the outcome of chlamydial infection. Curr Opin Immunol 2002;14(4):444-51.

[50] Saikku P. Chlamydia pneumoniae - an update on clinical disease. In: Schachter J, Christiansen G, Clarke IN, editors. Chlamydia infections. Proceedings of 10th International Symposium on Human Chlamydial Infections, Antalya, Turkey; 2000. p. 443-53.
[51] Schmutzhard E. Viral infections of the CNS with special emphasis on Herpes simplex infections. J Neurol 2001;248(6):46977.

[52] Schwimmbeck PL, Dyrberg T, Drachman DB, Oldstone MB. Molecular mimicry and myasthenia gravis. An autoantigenic site of the acetylcholine receptor alpha-subunit that has biologic activity and reacts immunochemically with Herpes simplex virus. J Clin Invest 1989;84(4):1174-80.

[53] Sequiera LW, Jennings LC, Carrasco LH, Lord MA, Curry A, Sutton RN. Detection of herpes-simplex viral genome in brain tissue. Lancet 1979;2(8143):609-12.

[54] Singh N, Paterson DL. Encephalitis caused by human herpesvirus6 in transplant recipients: relevance of a novel neurotropic virus. Transplantation 2000;69(12):2474-9.

[55] Sriram S, Stratton CW, Yao S, Tharp A, Ding L, Bannan JD, et al. Chlamydia pneumoniae infection of the central nervous system in multiple sclerosis. Ann Neurol 1999;46(1):6-14.

[56] Sulowicz W, Ignacak E, Kuzniewski M, SzymczakiewiczMultanowska A, Zawilinska B, Kryczko E, et al. Cytomegalovirus infection in kidney transplant patients: clinical manifestations and diagnosis. Zentralbl Bakteriol 1998;287(4):489-500.

[57] Taylor GR, Crow TJ, Markakis DA, Lofthouse R, Neeley S, Carter GI. Herpes simplex virus and Alzheimer's disease: a search for virus DNA by spot hybridisation. J Neurol Neurosurg Psychiatry 1984;47(10):1061-5.

[58] Taylor GS, Vipond IB, Paul ID, Matthews S, Wilcock GK, Caul EO, et al. Failure to correlate C. pneumoniae with late onset Alzheimer's disease. Neurology 2002;59(1):142-3.

[59] Wagner EK, Bloom DC. Experimental investigation of Herpes simplex virus latency. Clin Microbiol Rev 1997;10(3):419-43.

[60] Whitley RJ, Gnann JW. Viral encephalitis: familiar infections and emerging pathogens. Lancet 2002;359(9305):507-13.

[61] Wolf R, Wolf D, Orion E, Matz H. Long-term prophylactic antiviral therapy for recurrent Herpes simplex: the controversy goes on. Clin Dermatol 2003;21(2):164-7.

[62] Yamaguchi H, Friedman H, Yamamoto Y. Involvement of nicotinic acetylcholine receptors in controlling Chlamydia pneumoniae growth in epithelial HEp-2 cells. Infect Immun 2003;71(6):3645-7. 